\title{
Pedicled sural flaps versus free anterolateral thigh flaps in reconstruction of dorsal foot and ankle defects in children: a systematic review
}

\author{
Suzanne M. Beecher, Kevin C. Cahill, Christoph Theopold \\ Department of Plastic and Reconstructive Surgery, St. James's Hospital, Dublin, Ireland
}

Background This systematic review compared free anterolateral thigh (ALT) flaps versus pedicled distally based sural artery (DBSA) flaps for reconstruction of soft tissue defects of dorsal foot and ankle in children.

Methods A systematic literature search was performed to identify cases where an ALT or DBSA was used to reconstruct the dorsal foot in children. A total of 19 articles were included in the systematic review.

Results Eighty-three patients underwent an ALT reconstruction and 138 patients underwent a DBSA reconstruction. Patients who had a DBSA were more likely to require grafting of the donor site $(P<0.001)$. The size of ALT flaps was significantly larger than DBSA flaps $(P=0.002)$. Subsequent flap thinning was required in $30 \%$ of patients after ALT and $12 \%$ of patients after DBSA reconstruction $(\mathrm{P}<0.001)$. Complications occurred in $11.6 \%$ of DBSA and $8.4 \%$ of ALT flaps (8.4\%).

Conclusions Both flaps are valid options in reconstructing pediatric foot and ankle defects. Each flap has advantages and disadvantages as discussed in this review article. In general for larger defects, an ALT flap was used. Flap choice should be based on the size of the defect.

Keywords Foot reconstruction / Pediatric / Reconstruction / Microsurgery

Received: May 30, 2020 • Revised: April 2, 2021 • Accepted: April 9, 2021

pISSN: 2234-6163 • elSSN: 2234-6171 • https://doi.org/10.5999/aps.2020.00983 • Arch Plast Surg 2021;48:410-416

\author{
Correspondence: \\ Suzanne M. Beecher \\ Department of Plastic and \\ Reconstructive Surgery, St. James's \\ Hospital, Dublin 8, Ireland \\ Tel: $+353-1-4162652$ \\ Fax: +353-1-4103432 \\ E-mail:suzub@hotmail.com
}

\section{INTRODUCTION}

Pediatric foot and ankle trauma can be a devastating injury. Common etiologies include road traffic accidents, crush injuries and machinery injuries (e.g., lawnmowers). Firearm and burn injuries can also require soft tissue reconstruction.

It is often a challenging scenario to reconstruct soft tissue defects of these foot and ankle injuries in children. The wound base may render them unsuitable for split or full-thickness skin grafts. Local skin flap options are often limited or lacking in these areas. Thus, pedicled locoregional flaps or free tissue transfer of flaps are often necessary to reconstruct these injuries.

There has been a steady shift in the management of these complex wounds over time. Traditionally, for free tissue transfer, muscle-based free flaps would have been used to resurface lower limb soft tissue defects [1]. Previously, muscle flaps were felt to be superior to fasciocutaneous flaps for coverage of exposed bone, as the increased vascularity of muscle was thought to improve healing at the wound base. This however is no longer felt to be true, as fasciocutaneous flaps were found to have a higher 
vascular density in contact with bone [2]. Fasciocutaneous flaps are now gaining popularity as they have a lower donor site morbidity and have greater versatility. Thinner flaps are more favorable on the ankle and foot as they allow for normal footwear and allow tendon gliding and ankle movement [3]. Also, fasciocutaneous flaps are easier to re-elevate for subsequent procedures. Whilst the anterolateral thigh (ALT) flap is a reliable option for foot and ankle reconstruction, the caliber of vessels in the pediatric population can be small, leading to a potentially increased difficulty with microsurgical anastomosis.

Pedicled fasciocutaneous flaps can also be used to resurface complex wounds of the foot and ankle. The pedicled distally based sural artery (DBSA) flap is a reliable and well-described option for soft tissue reconstruction of the foot and ankle. It has the advantage, particularly in children, of avoiding a potentially technically challenging microsurgical procedure.

There is a paucity of published articles in the literature comparing methods of foot and ankle reconstruction in the pediatric population. This systematic review aimed to compare free ALT flaps versus pedicled DBSA flaps for reconstruction of soft tissue defects of the ankle and dorsal foot surface in children.

\section{METHODS}

A systematic review was performed by searching Scopus, Cochrane, and PubMed databases. The PRISMA (Preferred Reporting Items for Systematic Reviews and Meta-Analyses) guidelines were accessed and followed during the study [4]. The keywords "paediatric," "pediatric," "child," "foot," "ankle," "flap," and "reconstruction" were used as search strings. The bibliography of articles retrieved was also searched to identify relevant articles.

Articles that reported the outcome of DBSA or ALT reconstruction of traumatic pediatric ankle and dorsal foot defects were included in the study. For inclusion in the systematic review, the minimum outcome dataset in the publication had to include the location of the defect, the type of surgical reconstruction, the total number of patients, patient age 16 years or younger, the total number of reconstructions, complications and outcome. Studies, where there was a mixed cohort of adult and pediatric patients were included if there was the minimum dataset available on the pediatric patients. Single case reports and letters, were included if they met the inclusion criteria. Exclusion criteria included inability to access the publication's full text, articles not available in the English language, defects in weight-bearing parts of the foot or if the flap was for an etiology other than trauma.

A single reviewer performed the initial article title search of all the databases. Duplicate articles were deleted. Each article abstract was then reviewed. Articles that were deemed relevant based on the abstract review underwent review of the full text of the publication. Articles that were not clearly excluded based on abstract review also underwent full text review. After review of the full text articles, the publications that were deemed relevant were analyzed. The quality of the included studies was evaluated using the Quality Assessment Tool for Case Series Studies [5].

Association between categorical factors of interest were analyzed using the Pearson chi-square test of association and independent t-test. $\mathrm{P}<0.05$ was considered statistically significant. All analyses were performed using SPSS version 21 (IBM Corp., Armonk, NY, USA).

\section{RESULTS}

A total of 97 relevant titles of articles were identified in the literature search. Thirty-four articles were excluded as they did not meet the full inclusion and exclusion criteria. Thus, 63 articles were included in the full text publication review. After review of the full text articles, a further 44 articles were excluded as they did not meet the inclusion or exclusion criteria (Fig. 1). A total of 19 articles were therefore included in the systematic review [6-24]. These included a total number of articles of 13 on DBSA reconstruction and six on ALT reconstructions of pediatric dorsal foot defects. A total number of 221 patients were included in the review. The quality of the studies included using the Quality Assessment Tool for Case Series Studies Checklist is detailed in the Supplemental Materials 1 and 2.

\section{Patient characteristics}

The mean patient age was 8.2 years, with a range of 3 to 16

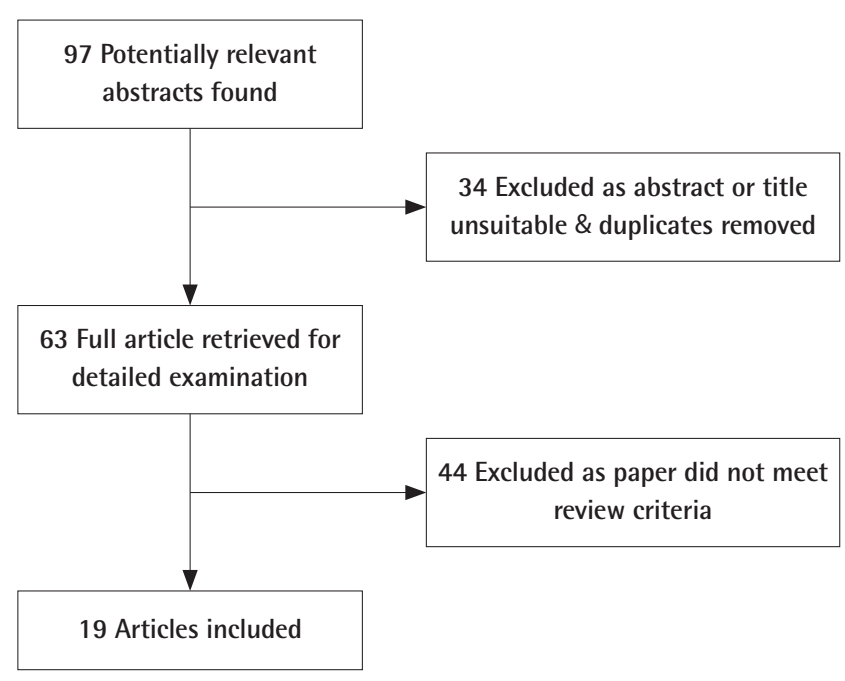

Fig. 1. Flowchart describing the literature review. 
Table 1. Patient and flap demographics

\begin{tabular}{|c|c|c|c|c|c|c|}
\hline First author (yr) & Total No. & $\begin{array}{c}\text { Age }(\mathrm{yr}), \\
\text { mean (range) }\end{array}$ & $\operatorname{Sex}(M / F)$ & Cause & $\begin{array}{l}\text { Mean flap size } \\
(\mathrm{cm})\end{array}$ & $\begin{array}{c}\text { Follow-up (mo), } \\
\text { mean (range) }\end{array}$ \\
\hline \multicolumn{7}{|l|}{ Anterolateral thigh } \\
\hline Acar (2015) [6] & 8 & $19(3-15)$ & $5 / 3$ & 3 Gun, 1 bike, 4 RTA & $10 \times 7.2$ & $19(13-29)$ \\
\hline Demirtas (2010) [9] & 5 & $4.8(4-6)$ & $4 / 1$ & 5 RTA & $10.2 \times 5.6$ & $27.4(18-41)$ \\
\hline El-Gammal (2013) [10] & 42 & 6.2 & $32 / 10$ & 3 Crush, 39 RTA & $15.5 \times 7.4$ & 42 \\
\hline $\mathrm{Hu}(2015)[12]$ & 25 & $8.3(4-12)$ & $16 / 9$ & 14 RTA, 7 bike, 4 machine & $12.5 \times 8$ & 14.2 \\
\hline Li (2012) [15] & 1 & 6 & $1 / 0$ & 1 RTA & Unknown & 8 \\
\hline Ozkan (2004) [19] & 2 & $12.5(9-16)$ & $2 / 0$ & 1 Bike, 1 crush & $12.5 \times 6.5$ & Unknown \\
\hline \multicolumn{7}{|l|}{ Sural } \\
\hline Almeida (2002) [7] & 3 & $14(12-16)$ & $1 / 2$ & 2 RTA, 1 fall & $8.5 \times 6.8$ & Unknown \\
\hline Chai (2007) [8] & 2 & $9.5(5-14)$ & $0 / 2$ & 2 Trauma & $20 \times 8$ & $15(6-24)$ \\
\hline Grandjean (2016) [11] & 13 & $6.9(4-13)$ & Unknown & 1 Burn, 3 LM, 8 RTA, 1 bike & Unknown & $58(10-192)$ \\
\hline Kim (2014) [13] & 3 & 7 (6-8) & 2/1 & 3 RTA & $17 \times 5.3$ & $97(88-102)$ \\
\hline Koladi (2003) [14] & 10 & $7.1(4-9)$ & $7 / 3$ & 10 Trauma & $5.1 \times 3.6$ & Unknown \\
\hline Liu (2013) [16] & 31 & 9 & $23 / 8$ & 31 Trauma & $5 \times 4$ to $12 \times 8$ & 32 \\
\hline Mahmood (2011) [17] & 16 & $7.37 \mathrm{mo}$ & $10 / 6$ & 16 Trauma & $3 \times 4$ to $5 \times 9$ & Unknown \\
\hline Olawoye (2014) [18] & 2 & $12(8-16)$ & $1 / 1$ & 2 Trauma & $9 \times 7$ & Unknown \\
\hline Parajuli (2014) [20] & 3 & $13.3(12-14)$ & $1 / 2$ & 3 RTA & $8 \times 5.7$ & Unknown \\
\hline Rajacic (1996) [21] & 8 & $6.5(3-16)$ & $5 / 3$ & 8 Trauma & $7.1 \times 4.4$ & Unknown \\
\hline Tan (2015) [22] & 1 & 12 & $0 / 1$ & 1 RTA & $8 \times 6$ & 30 \\
\hline Vergara-Amador (2009) [23] & 16 & 9 & Unknown & 1 Machine, 15 RTA & Unknown & 8 \\
\hline Zheng (2016) [24] & 30 & $8.2(3-12)$ & $24 / 6$ & 24 RTA, 6 bike & $9.7 \times 6.4$ & Unknown \\
\hline
\end{tabular}

M, male; F, female; RTA, road traffic accident; LM, lawnmower.

years. There were 134 males and 58 females. The gender of the patient was unknown in 29 cases. The mean patient follow-up was 40.5 months, with a range of 6 to 192 months (Table 1).

\section{Etiology of foot injuries}

Soft tissue defects of the foot and ankle were most commonly caused by a road traffic accident, with 119 children injured. Bicycle injuries were also common, with 16 cases attributed. There were five cases where the injury was caused by a machine, but not specified. A further three cases were caused by a lawnmower. Four children sustained a crush injury to the foot. There were three cases of gunshot wounds in the review. One burn required flap reconstruction in the acute phase. One case was subsequent to a fall injury. Twenty-four patients had trauma that was not further defined by the publication.

\section{Reconstructive options}

Eighty-three patients underwent an ALT flap reconstruction and 138 patients underwent a DBSA flap reconstruction of the foot or ankle defect. Study sizes ranged from 1 to 42 cases. The largest study accounted for $17.6 \%$ of the dataset population.

The mean ALT flap length and width were $11.8 \mathrm{~cm}$ (standard deviation $[\mathrm{SD}], 2.82)$ and $7.4 \mathrm{~cm}(\mathrm{SD}, 2.03)$ respectively. The mean DBSA flap length and width were $9.1 \mathrm{~cm}(\mathrm{SD}, 4.15)$ and $5.7 \mathrm{~cm}$ (SD, 2.09) respectively. Flaps were longer with ALT flaps compared to DBSA flaps $(\mathrm{P}=0.001)$. Flaps were also wider with ALT flaps compared to DBSA flaps $(\mathrm{P}<0.001)$. The mean surface area for ALT flaps was $91.7 \mathrm{~cm}^{2}$ (SD, 45.2; range, 40216). The DBSA flaps had a mean surface area of $57.9 \mathrm{~cm}^{2}$ (SD, 40.7; range, 6-200). The size of ALT flaps was significantly larger than DBSA flaps $(\mathrm{P}=0.002)$.

The patients who had an ALT flap harvested, the donor site was closed primarily in 57 (69\%) cases and grafted in 20 (24\%) cases (Table 2). The method of closure was unknown in six cases. In $26(19 \%)$ cases of DBSA reconstruction, the donor site was closed primarily. Sixty-five (47\%) patients required grafting of the donor site. Those who underwent DBSA reconstruction were more likely to require grafting at the donor site $(\mathrm{P}<0.001)$. The method of donor closure for sural flap was unknown in 47 cases. Unfortunately, a comparison on the rate of grafting based on flap size could not be made sure to a lack of data provided in the articles. There was a statistically significant increased incidence of subsequent flap thinning required after ALT flap reconstruction compared to after DBSA flap reconstruction 17 ( $30 \%$ vs. $12 \%)(\mathrm{P}<0.001)$. The rate of flap thinning was not reported in 60 cases.

\section{Complications}

The overall perioperative flap-related complication rate for all flaps was $10 \%(n=23)$. Complications included infection, ve- 
Table 2. Flap characteristics

\begin{tabular}{|c|c|c|c|c|}
\hline First author (yr) & $\begin{array}{c}\text { No. of } \\
\text { patients }\end{array}$ & $\begin{array}{l}\text { Donor } \\
\text { closure }\end{array}$ & $\begin{array}{l}\text { Late flap } \\
\text { thinning }\end{array}$ & $\begin{array}{l}\text { Specialized } \\
\text { footwear }\end{array}$ \\
\hline \multicolumn{5}{|l|}{ Anterolateral thigh } \\
\hline Acar (2015) [6] & 8 & $8 P$ & 4 & U \\
\hline Demirtas (2010) [9] & 5 & $5 \mathrm{U}$ & 0 & 0 \\
\hline El-Gammal (2013) [10] & 42 & $25 \mathrm{P}, 17 \mathrm{G}$ & 16 & 15 \\
\hline $\mathrm{Hu}(2015)$ [12] & 25 & $22 P, 3 \mathrm{G}$ & 5 & 5 \\
\hline Li (2012) [15] & 1 & U & 0 & 0 \\
\hline Ozkan (2004) [19] & 2 & $2 P$ & U & U \\
\hline \multicolumn{5}{|l|}{ Sural } \\
\hline Almeida (2002) [7] & 3 & $3 G$ & U & U \\
\hline Chai (2007) [8] & 2 & $1 \mathrm{G}, 1 \mathrm{U}$ & U & U \\
\hline Grandjean (2016) [11] & 13 & $13 \mathrm{G}$ & U & U \\
\hline Kim (2014) [13] & 3 & 3 P-aff & U & U \\
\hline Koladi (2003) [14] & 10 & U & U & U \\
\hline Liu (2013) [16] & 31 & $19 \mathrm{G}, 12 \mathrm{P}$ & 0 & 0 \\
\hline Mahmood (2011) [17] & 16 & U & 1 & U \\
\hline Olawoye (2014) [18] & 2 & $2 P$ & U & U \\
\hline Parajuli (2014) [20] & 2 & U & U & U \\
\hline Rajacic (1996) [21] & 8 & $3 \mathrm{G}, 5 \mathrm{P}$ & U & U \\
\hline $\operatorname{Tan}(2015)$ [22] & 1 & U & U & U \\
\hline Vergara-Amador (2009) [23] & 16 & U & U & 1 \\
\hline Zheng (2016) [24] & 30 & $26 \mathrm{G}, 4 \mathrm{P}$ & 16 & U \\
\hline
\end{tabular}

P, primary closure; U, unknown; G, skin graft; aff, adipofascial flap.

nous congestion, ulceration and partial or full-thickness necrosis (Table 3). A complication occurred in 16 of the DBSA flaps (11.6\%) and seven of the ALT flaps (8.4\%). Venous congestion was reported in 6\% of DBSA flaps and in $4.8 \%$ of ALT flaps. There increased risk of venous congestion between flaps was not statistically significant $(\mathrm{P}=0.756)$. Partial flap necrosis occurred in eight DBSA flaps (6\%) and three flaps underwent total flap failure (2\%). Partial flap necrosis occurred in five ALT flaps $(6 \%)$ and total flap necrosis occurred in one patient $(1.2 \%)$. There was no statistically significance between the incidences of partial or total flap necrosis between the two methods $(\mathrm{P}=0.945$ and $\mathrm{P}=0.601)$. Postoperative hematoma occurred after one ALT flap. Infection occurred in three sural flaps and one ALT flap. Two DBSA flaps developed ulceration.

Long-term complications at the donor site included hypertrophic or keloid scars. In the flap donor area in the calf, four patients developed a hypertrophic scar after DBSA flap harvest (2.9\%). Four patients developed a hypertrophic scar and three patients developed a keloid scar in the donor area of the thigh after ALT flap harvest.

\section{DISCUSSION}

The management of soft tissue loss of the lower limb has changed dramatically over the past few decades, in both adults and children. In early years, complex wounds that required re-
Table 3. Flap complications

\begin{tabular}{|c|c|c|c|c|c|}
\hline First author (yr) & $\begin{array}{l}\text { No. of } \\
\text { patients }\end{array}$ & Necrosis & $\begin{array}{l}\text { Flap } \\
\text { failure }\end{array}$ & Scar & $\begin{array}{c}\text { Other } \\
\text { complication }\end{array}$ \\
\hline \multicolumn{6}{|l|}{ Anterolateral thigh } \\
\hline Acar (2015) [6] & 8 & $1 P$ & 0 & $2 \mathrm{HS}$ & $1 \mathrm{VC}$ \\
\hline Demirtas (2010) [9] & 5 & 0 & 0 & 0 & $1 \mathrm{H}, 1 \mathrm{I}$ \\
\hline El-Gammal (2013) [10] & 42 & $2 \mathrm{P}, 1 \mathrm{~F}$ & 1 & $3 \mathrm{~K}, 2 \mathrm{HS}$ & $3 \mathrm{VC}$ \\
\hline $\mathrm{Hu}(2015)[12]$ & 25 & $2 \mathrm{P}$ & 0 & U & 0 \\
\hline Li (2012) [15] & 1 & 0 & 0 & U & 0 \\
\hline Ozkan (2004) [19] & 2 & 0 & 0 & U & 0 \\
\hline \multicolumn{6}{|l|}{ Sural } \\
\hline Almeida (2002) [7] & 3 & $1 \mathrm{P}$ & 0 & U & 0 \\
\hline Chai (2007) [8] & 2 & 0 & 0 & $U$ & 0 \\
\hline Grandjean (2016) [11] & 13 & $2 \mathrm{P}$ & 0 & $3 \mathrm{HS}$ & $2 \mathrm{VC}, 1 \mathrm{I}$ \\
\hline Kim (2014) [13] & 3 & 0 & & U & 11 \\
\hline Koladi (2003) [14] & 10 & 0 & 0 & U & 11 \\
\hline Liu (2013) [16] & 31 & 0 & 0 & $U$ & $3 \mathrm{VC}$ \\
\hline Mahmood (2011) [17] & 16 & $1 \mathrm{~F}, 1 \mathrm{P}$ & 1 & $1 \mathrm{HS}$ & 0 \\
\hline Olawoye (2014) [18] & 2 & 0 & 0 & U & 0 \\
\hline Parajuli (2014) [20] & 3 & $1 \mathrm{~F}$ & 1 & U & 0 \\
\hline Rajacic (1996) [21] & 8 & $1 P$ & 0 & U & 0 \\
\hline Tan (2015) [22] & 1 & 0 & 0 & U & 0 \\
\hline $\begin{array}{l}\text { Vergara-Amador } \\
\text { (2009) [23] }\end{array}$ & 16 & $2 \mathrm{P}, 1 \mathrm{~F}$ & 1 & & $3 \mathrm{VC}$ \\
\hline Zheng (2016) [24] & 30 & $1 \mathrm{P}$ & 0 & $U$ & 2 Ulcer \\
\hline
\end{tabular}

P, partial; HS, hypertrophic donor scar; VC, venous congestion; H, hematoma; I, infection; F, full; K, keloid donor; U, unknown.

construction and that were unsuitable for skin grafts, would have been managed either by amputation or by a cross leg flap. In the 1980's muscle-based free flaps became popular to manage complex wounds of the foot and ankle [25]. In more recent years, fasciocutaneous and perforator flaps, both pedicled and free, have been increasingly advocated as the perceived advantages of muscle flaps are felt to be less clear-cut than originally assumed. There has been a conceptual shift from the reconstructive ladder to the reconstructive armamentarium in choosing the method of reconstruction of defects, that is, the reconstructive method should be chosen not on the simplest method available, rather the best suited option for reconstruction should be chosen based on the defect.

In resurfacing the skin of the dorsal foot and ankle, the flap must be thin and pliable to allow for tendon gliding and significant excursion to permit the use of regular footwear and effective postoperative mobilization [10]. There are several pedicled and free flap options available to reconstruct foot and ankle defects in children. Multiple factors can influence the method of reconstruction of pediatric foot and ankle defects, such as the need for mobility across the ankle joint, the need for a sensate flap, or the need for composite tissue transfer to reconstruct tendons or ligaments. There is a paucity of literature directly addressing which flap is superior, where the requirements of the 
wound do not mandate a specific reconstruction.

The ALT flap was first described by Song et al. [26] in 1984. It is a fasciocutaneous flap that bases its blood supply on the descending branch of the lateral femoral circumflex artery. In the foot and ankle, the vessels can be anastomosed to the anterior tibial or the posterior tibial vessels. Advantages include its reduced donor site morbidity compared to muscle-based free flaps. On the foot it can expand as the child's foot grows [27]. The iliotibial band can also be harvested with the ALT flap to reconstruct the Achilles tendon and other tendons and ligaments [12]. A sensate flap is also possible with the ALT flap by coapting the lateral femoral cutaneous nerve of the thigh to the saphenous nerve [15]. The flap can also be aggressively thinned to conform to the dorsal foot [28]. Another advantage is that is can often be closed primarily with flap widths up to $8 \mathrm{~cm}$.

The major disadvantage of the free ALT flap is that it requires microsurgical anastomosis. Previously it was thought that microsurgery in the pediatric population was challenging and should be avoided if possible. It is often assumed that blood vessels in children are very small and require great skill to anastomose. They are however not as small as might be expected [29]. Momeni et al. [30] feel that microsurgery may be more successful as the patients rarely have vasculopathy or venous insufficiency, and pediatric patients are typically not smokers. In their study, they also showed that free tissue transfer in children can have equivalent rates of success in comparison to adults.

The distally based sural flap was first introduced by Masquelet et al. [31] in 1992. It is a neurocutaneous flap that bases its blood supply from arteries accompanying the superficial sensory sural nerve. The arterial supply is based on a terminal perforating branch of the peroneal artery. The perforators pass between the fibula and flexor hallucis longus proximally and between soleus and peroneus longus muscles distally in the leg. Advantages of the flap include its constant vascular supply and its ability to rotate to various areas. Flap raising is relatively simple and rapid, and the pedicled nature of the flap avoids the need for microsurgical anastomosis. The sural flap can also be harvested as an adipofascial flap [13]. Adipofascial flaps have the advantage of being thin and pliable and reduce donor site morbidity. Adipofascial flaps however usually require skin graft coverage, which can result in an inferior aesthetic result.

There are disadvantages to the sural flap. These include venous congestion of the flap and potential necrosis due to limited flap rotation as the pedicle can become twisted and compressed [8]. Venous congestion can be reduced by ligating the lesser saphenous vein at the proximal and distal ends of the flap to avoid continuous venous inflow [8]. The incidence of marginal flap necrosis can be reduced by avoiding detachment of the skin from the fascia. This can be reduced by suturing them together during flap raising [8]. Sural flaps can also be quite bulky. However, in contrast to ALT flaps, owing to their vascular anatomy, they cannot be aggressively thinned during the primary procedure [32]. A dog-ear deformity can also occur at the pivot point if an interpolated flap is used, which may necessitate revision surgery [33]. Another potential disadvantage is that the donor site often requires skin grafting for defects wider than $4-5 \mathrm{~cm}$. This may result in a worse cosmetic outcome of the lower limb. In comparison to the ALT flap, the donor site of the sural flap is less concealable.

This study is limited due to the heterogeneity between studies and the inconsistent provision of data. Therefore, a meta-analysis of the necessity of grafting of the donor site based on flap size could not be performed.

In conclusion, this systematic review is the first comparing pedicled flaps to free flaps in reconstruction of foot and ankle defects in children. This review did not find that one flap was superior to the other in terms of complication rates. Both the ALT flap and the distally based sural flap are valid options in reconstructing pediatric foot and ankle defects. Each flap has advantages and disadvantages as discussed in this review article. In general, larger flaps were harvested in the case where ALT flaps were used, suggesting that larger defects require free tissue transfer. We suggest in cases where primary closure of the calf is possible, a DBSA flap is a good option. For larger defects, free tissue transfer with an ALT flap should be considered.

\section{NOTES}

\section{Conflict of interest}

No potential conflict of interest relevant to this article was reported.

\section{Author contribution}

Conceptualization: SM Beecher. Data curation: SM Beecher. Formal analysis: SM Beecher. Methodology: SM Beecher. Writing - original draft: SM Beecher. Writing - review \& editing: KC Cahill, C Theopold.

\section{ORCID}

Suzanne M. Beecher https://orcid.org/0000-0001-6489-3424

Kevin C. Cahill https://orcid.org/0000-0002-1016-9673

Christoph Theopold https://orcid.org/0000-0003-2031-6355

\section{Supplementary material}

Supplemental Material 1. PRISMA checklist. Supplemental data can be found at: https://doi.org/10.5999/aps.2020.00983. 
Supplemental Material 2. Quality Assessment Data. Supplemental data can be found at: https://doi.org/10.5999/aps.2020.00983.

\section{REFERENCES}

1. Hallock GG. A paradigm shift in flap selection protocols for zones of the lower extremity using perforator flaps. J Reconstr Microsurg 2013;29:233-40.

2. Harry LE, Sandison A, Pearse MF, et al. Comparison of the vascularity of fasciocutaneous tissue and muscle for coverage of open tibial fractures. Plast Reconstr Surg 2009;124: 1211-9.

3. Nuzumlali E, Gurbuz C, Kantarci U, et al. Moving car-tire injuries of the foot: reconstruction with microvascular free flaps. J Reconstr Microsurg 1996;12:297-302.

4. PRISMA Checklist [Internet]. PRISMA [cited 2021 Apr 2]. Available from: http://prisma-statement.org/PRISMAStatement/Checklist.

5. National Heart, Lung, and Blood Institute. Quality Assessment Tool for Case Series Studies [Internet]. Bethesda, MD: National Institutes of Health; c2014 [cited 2021 Apr 2]. Available from: https://www.nhlbi.nih.gov/health-topics/ study-quality-assessment-tools.

6. Acar MA, Gulec A, Aydin BK, et al. Reconstruction of foot and ankle defects with a free anterolateral thigh flap in pediatric patients. J Reconstr Microsurg 2015;31:225-32.

7. Almeida MF, da Costa PR, Okawa RY. Reverse-flow island sural flap. Plast Reconstr Surg 2002;109:583-91.

8. Chai Y, Zeng B, Zhang F, et al. Experience with the distally based sural neurofasciocutaneous flap supplied by the terminal perforator of peroneal vessels for ankle and foot reconstruction. Ann Plast Surg 2007;59:526-31.

9. Demirtas Y, Neimetzade T, Kelahmetoglu O, et al. Free anterolateral thigh flap for reconstruction of car tire injuries of children's feet. Foot Ankle Int 2010;31:47-52.

10. El-Gammal TA, El-Sayed A, Kotb MM, et al. Dorsal foot resurfacing using free anterolateral thigh (ALT) flap in children. Microsurgery 2013;33:259-64.

11. Grandjean A, Romana C, Fitoussi F. Distally based sural flap for ankle and foot coverage in children. Orthop Traumatol Surg Res 2016;102:111-6.

12. Hu R, Ren YJ, Yan L, et al. A free anterolateral thigh flap and iliotibial band for reconstruction of soft tissue defects at children's feet and ankles. Injury 2015;46:2019-23.

13. Kim MB, Lee YH, Kim JH, et al. Distally based adipofascial flaps covering soft-tissue defects of the dorsal foot and ankle in children. Ann Plast Surg 2014;73:568-77.

14. Koladi J, Gang RK, Hamza AA, et al. Versatility of the distal- ly based superficial sural flap for reconstruction of lower leg and foot in children.J Pediatr Orthop 2003;23:194-8.

15. Li RG, Yu B, Wang G, et al. Sequential therapy of vacuum sealing drainage and free-flap transplantation for children with extensive soft-tissue defects below the knee in the extremities. Injury 2012;43:822-8.

16. Liu L, Liu Y, Zou L, et al. The distally based superficial sural flap for reconstruction of the foot and ankle in pediatric patients. J Reconstr Microsurg 2013;29:199-204.

17. Mahmood F, Mehrose MY, Tasneem S, et al. Distally based superficial sural artery flap for foot and ankle reconstruction in children.J Ayub Med Coll Abbottabad 2011;23:40-2.

18. Olawoye OA, Ademola SA, Iyun $\mathrm{K}$, et al. The reverse sural artery flap for the reconstruction of distal third of the leg and foot. Int Wound J 2014;11:210-4.

19. Ozkan O, Coskunfirat OK, Ozgentas HE. An ideal and versatile material for soft-tissue coverage: experiences with most modifications of the anterolateral thigh flap.J Reconstr Microsurg 2004;20:377-83.

20. Parajuli NP, Shrestha D, Panse N. Distally based sural faciocutaneous and fascial (adipofascial) flap for reconstruction of distal leg, ankle and foot defects. Kathmandu Univ Med J (KUMJ) 2014;12:126-31.

21. Rajacic N, Darweesh M, Jayakrishnan K, et al. The distally based superficial sural flap for reconstruction of the lower leg and foot. Br J Plast Surg 1996;49:383-9.

22. Tan O, Aydin OE, Demir R, et al. Neurotized sural flap: an alternative in sensory reconstruction of the foot and ankle defects. Microsurgery 2015;35:183-9.

23. Vergara-Amador E. Distally-based superficial sural neurocutaneous flap for reconstruction of the ankle and foot in children. J Plast Reconstr Aesthet Surg 2009;62:1087-93.

24. Zheng H, Liu J, Dai X, et al. The distally based sural flap for the reconstruction of ankle and foot defects in pediatric patients. Ann Plast Surg 2016;77:97-101.

25. Boeckx W, van den Hof B, van Holder C, et al. Changes in donor site selection in lower limb free flap reconstructions. Microsurgery 1996;17:380-5.

26. Song YG, Chen GZ, Song YL. The free thigh flap: a new free flap concept based on the septocutaneous artery. Br J Plast Surg 1984;37:149-59.

27. Cho JY, Suh HS, Hong JP. Do skin perforator flaps accommodate foot growth in children after reconstruction? J Reconstr Microsurg 2016;32:650-6.

28. Viviano SL, Liu FC, Therattil PJ, et al. Peripheral pruning: a safe approach to thinning extra-large anterolateral thigh flaps. Ann Plast Surg 2018;80(4 Suppl 4):S164-7.

29. Noaman HH. Microsurgery in children: history, indications, 
precautions, and differences from that of adults. Microsurgery 2008;28:83-4.

30. Momeni A, Lanni M, Levin LS, et al. Microsurgical reconstruction of traumatic lower extremity defects in the pediatric population. Plast Reconstr Surg 2017;139:998-1004.

31. Masquelet AC, Romana MC, Wolf G. Skin island flaps supplied by the vascular axis of the sensitive superficial nerves: anatomic study and clinical experience in the leg. Plast Reconstr Surg 1992;89:1115-21.

32. Park SO, Chang H, Imanishi N. Anatomic basis for flap thinning. Arch Plast Surg 2018;45:298-303.

33. Maffi TR, Knoetgen J 3rd, Turner NS, et al. Enhanced survival using the distally based sural artery interpolation flap. Ann Plast Surg 2005;54:302-5. 